\title{
UM SONHO DE EXAME: CONSIDERAÇÕES SOBRE CASA DE PENSÃo de AluísIo AZEVEdo ${ }^{441}$
}

\author{
DURVAL MARCONDES
}

Estudando os sonhos típicos, isto é, sonhos que quase todos nós sonhamos da mesma forma e que devem ter, portanto, a mesma significação em todos os indivíduos, estende-se Freud longamente na apreciação do "sonho de exame". 442

É, com efeito, relativamente comum, mesmo que já se tenha terminado há bastante tempo a vida escolar, sonhar-se que se está prestando um exame muito difícil com o risco e o medo de uma reprovação. Nesse sonho, que costuma surgir nas noites que precedem a execução de alguma tarefa difícil e comprometedora, revive, segundo Freud, a recordação dos castigos a que fizemos jus pelas faltas cometidas durante a nossa infância. $\mathrm{O}$ "medo de exame" dos neuróticos está do mesmo modo, ligado a essa angústia infantil.

Terminados [escreve Freud] os nossos estudos, não é mais de nossos pais, preceptores ou mestres, que devemos esperar o castigo de nossas culpas, mas da inexorável concatenação causal da vida, que toma a si continuar nossa educação, e é então que sonhamos com os exames - e quem não terá alguma vez duvidado de seu êxito? Quando tememos que alguma coisa nos saia mal como castigo por não termos andado bem ou não termos recorrido aos meios suficientes para a obtenção de um fim desejado, isto é, sempre que sentimos pesar sobre nós uma responsabilidade.

Quero contar-lhes um interessantíssimo sonho de exame que, pelo seu próprio conteúdo, confirma plenamente essa afirmação de Freud. Trata-se do sonho de um indivíduo moço, estudante de medicina, que andava por essa época muito preocupado com uma ligação amorosa ilícita, cheia de responsabilidade, que, além de pesar-lhe monetária e moralmente, tinha-o prejudicado muito no preparo para o exame de fim de ano.

$\mathrm{Na}$ véspera do exame, sonhou que os examinadores surgiam-lhe, terríveis, ríspidos, armados de palmatória, e todos com aquela feia catadura do seu ex-professor de Português em sua terra natal. A prova acadêmica amesquinhava-se as ridículas proporções do exame de Primeiras Letras. Era a mesma salinha do mestre-escola, com os mesmos móveis, tudo como na sua infância. Amigos seus, que conhecera depois de adulto, lá estavam vestidos de menino, fitando o examinando com um riso de escárnio. O professor, transformado em juiz, e ostentando as feições de seu falecido pai, inquiria-o com aspereza, mas as suas perguntas, em vez de concernirem às matérias do ato, só se referiam a sua amante.

"- Porque matou você a pobre menina?! Bramia o pai, cravando-lhe olhares de fogo: Responda, seu canalha! Responda! Ah! Pensa que ainda não sei de que você, para melhor a seduzir, havia-lhe prometido casamento e jurado olhar sempre por ela, seu cachorro?!"

A amante jazia, realmente, morta e ensangüentada, ali mesmo.

O réu queria responder, justificar-se, expor a verdade; eram, porém, baldados os seus esforços, pois não conseguia articular uma só palavra.

“- Bem! Gritou o velho pai a alguns soldados que escoltavam o estudante. - Conduzam esse miserável ao cepo e cortem-lhe a cabeça!"

O estudante atirou-se de joelhos, com as mãos postas, chorando, suplicando que não o matassem. Mas os soldados apoderaram-se dele com violência e ataram-lhe os braços. $\mathrm{O}$ juiz e vários circunstantes sumiram de repente, soltando gargalhadas. O rapaz foi então

\footnotetext{
${ }^{441}$ Publicado originalmente na Revista Brasileira de Psicanálise, v. 1, 1928.

${ }^{442}$ Sigmund Freud, La interpretación de los sueños, Madrid, Ed. Biblioteca Nueva, v. I, p. 303.
} 
brutalmente conduzido por um corredor escuro até um pátio lajeado e úmido onde milhares de homens armados formavam alas; no centro, sobre um toro de madeira conspurcada de sangue, reluzia um machado a sua espera; e, de joelhos, abraçado a um crucifixo, um padre velho, de longos cabelos brancos, engrolava latim.

Fez-se silêncio.

No meio das respirações abafadas, só se ouviam os passos trôpegos e o aflitivo resfolegar do condenado que, à ponta de baioneta, subia os degraus do cadafalso.

Veio o carrasco, despiu-lhe a camisa, tosou-lhe os cabelos, e empunhou o ferro.

O estudante não se resolvia a entregar o pescoço, mas o velho pai, que surgira por de traz dele, atirou-lhe um murro à nuca e o fez cair de bruços contra o cepo.

Então, para lhe abafar os gemidos, romperam todos os soldados num rufo estridente de tambores.

O estudante sentiu o aço frio entrar-lhe na carne do toutiço, espipar o sangue, e o corpo, de um salto, arrojar-se às lajes.

Havia saltado, com efeito, mas da cama. E o despertador, que ficara de véspera com toda a corda para as seis da manhã, continuava o rufo penetrante dos tambores.

Nesse sonho, é evidente a intervenção do elemento infantil e, mais especificamente, do complexo paterno, pois o examinador, ou juiz, aparece identificado à imagem do pai. Além disso, o sonho tem lugar dentro das condições descritas pelo psiquiatra de Viena, isto é, quando o indivíduo sentia aproximar-se uma situação difícil, que ele agravara sensivelmente por sua própria fraqueza: se não tivesse se metido numa aventura amorosa, estaria provavelmente mais preparado para vencer nos exames.

Só havia uma objeção a fazer com respeito ao valor psicanalítico desse sonho: ele não foi sonhado por ninguém; foi criado pela imaginação de Aluísio Azevedo, que o atribui ao personagem principal de seu romance Casa de pensão. ${ }^{43}$ Isso, porém, não lhe tira absolutamente o interesse científico, pois é fato verificado por estudos de vários investigadores que os sonhos imaginados pelos artistas e incluídos em suas obras aparecem construídos conforme as leis descobertas pela psicanálise e se oferecem à interpretação como se fossem realmente sonhados. Entre as indagações feitas a esse respeito, cumpre destacar um valioso estudo de Freud sobre uma novela do escritor Jensen denominada Gradiva. Freud analisou certas idéias delirantes e alguns sonhos apresentados pelo protagonista dessa novela, concluindo que o verdadeiro artista possui um conhecimento intuitivo do mecanismo da atividade inconsciente e descobre em si mesmo, sem dar por isso, as leis que o psicanalista vai descobrir nos outros.

Nossa conduta, [escreve Freud], ${ }^{444}$ consiste na observação consciente dos processos psíquicos anormais das outras pessoas, com o fim de descobrir e expor as regras a que eles obedecem. O poeta procede de modo diferente: dirige sua atenção para seu próprio inconsciente, tateia as possibilidades de desenvolvimento de tais elementos e lhes permite chegar à expressão estética em lugar de reprimi-los por meio da crítica consciente. Desse modo, descobre em si mesmo aquilo que nós vamos verificar nos outros, isto é, as leis a que a atividade inconsciente tem que obedecer; porém não necessita expor essas leis, nem sequer aperceber-se perfeitamente delas, pois que, por efeito da tolerância de seu pensamento, elas passam a tomar parte na sua criação estética. $^{445}$

\footnotetext{
${ }^{443}$ Aluísio Azevedo, Casa de pensão, Rio/Paris, Ed. Livraria Garnier, p. 277.

${ }^{444}$ Sigmund Freud, "El delírio y los suenos", in La Gradiva, de W. Jensen, v. III das Obras completas, Madrid, Ed. Biblioteca Nueva, p. 409.

${ }^{445} \mathrm{~A}$ concepção psicanalítica do fenômeno da criação estética está exposta mais longamente no meu livro $O$ symbolismo esthetico na literatura, São Paulo, 1926.
} 
Pode-se, em vista disso, encarar o sonho criado por Aluísio Azevedo como se o personagem do romance tivesse realmente existido e procurar estabelecer as relações entre o conteúdo onírico e os complexos psicológicos desse personagem. E nesse ponto de vista a obra do nosso grande escritor é admirável de perfeição e de justeza, o que vale por uma confirmação dos princípios freudianos, pois me julgo autorizado a supor que Aluísio nunca teria lido nada de psicanálise...

Já vimos que o sonho em questão está perfeitamente de acordo com duas afirmações de Freud: em primeiro lugar, desenvolve-se numa ocasião em que o indivíduo devia enfrentar uma situação cheia de responsabilidade; em segundo lugar, está ligado a uma reminiscência infantil.

Se aprofundarmos um pouco mais nosso estudo e estendermos nossa indagação a outros pontos do entrecho do romance, verificaremos que o papel desempenhado no sonho pelo pai do protagonista é plenamente justificado pela sua atuação anterior, durante a vida infantil deste último, e como é fácil supor à luz da psicanálise, prende-se à intervenção de um complexo de Édipo. ${ }^{446}$

Amâncio fora muito mal educado pelo pai, português antigo e austero, desses que confundem o respeito com o terror. Em pequeno levou muita bordoada; tinha um medo horroroso de Vasconcelos; fugia dele como de um inimigo, e ficava todo frio e a tremer quando lhe ouvia a voz ou lhe sentia os passos. Se acaso algumas vezes se mostrava dócil e amoroso, era sempre por conveniência: habituou-se a fingir desde esse tempo.

Sua mãe, D. Ângela, uma santa de cabelos brancos e rosto de moça, não raro se voltava contra o marido e apadrinhava o filho. Amâncio agarrava-se-lhe às saias, fora de si, sufocado de soluços.

Aos sete anos entrou para a escola. Que horror!

O mestre, um tal Antonio Pires, homem grosseiro, bruto, de cabelo duro e olhos de touro, batia nas crianças por gosto, por um hábito do ofício. Na aula só falava a berrar, como se dirigisse uma boiada. Tinha as mãos grossas, a voz áspera, a catadura selvagem; e quando metia p'ra dentro um pouco mais de vinho, ficava pior.

Amâncio, já na Corte, só de pensar no bruto, ainda sentia, os calafrios dos outros tempos, e, com eles, vagos desejos de vingança. Um mal querer doentio invadia-lhe o coração, sempre que se lembrava do mestre e do pai. Envolvia-os no mesmo ressentimento, no mesmo ódio surdo e inconfessável.

Todos os pequenos da aula tinham birra ao Pires. Nele enxergavam o carrasco, o tirano, o inimigo e não o mestre; mas, visto que qualquer manifestação de antipatia redundava fatalmente em castigo, as pobres crianças fingiam-se satisfeitas; riam muito

\footnotetext{
${ }^{446}$ O complexo de Édipo consiste numa disposição sentimental em duas direções: atração sexual pela mãe e ódio ao pai. Quando, numa fase ainda primitiva do desenvolvimento psicossexual, a criança busca um objeto para sua libido, ela o encontra na pessoa do sexo oposto que lhe é mais achegada. Tratando-se de uma criança do sexo masculino, a ternura sexual se focaliza sobre a mãe, enquanto que o pai é tido como um usurpador dos carinhos maternos. Com o desenvolvimento geral do psiquismo e à força de repressão, tais idéias desaparecem, voltandose o impulso erótico do indivíduo para um objeto mais adequado. $\mathrm{O}$ trabalho psicológico do filho consiste, como ensina Freud (Introducción a la psicoanalisis, Madrid, Ed. Biblioteca Nueva, v. II, p. 140), em desligar de sua mãe os desejos libidinosos fazendo-os recair "sobre um objeto real não incestuoso, reconciliar-se com o pai, caso tenha conservado contra ele alguma hostilidade, ou emancipar-se de sua tirania quando, reagindo contra sua infantil rebelião, se tenha convertido num submisso escravo do mesmo. É este um trabalho que se impõe a todos os homens, mas que só em raros casos consegue alcançar um termo ideal, isto é, desenvolver-se de modo perfeito, tanto psicológica como socialmente. Os neuróticos fracassam nele por completo, permanecem toda a vida submetidos à autoridade paterna e são incapazes de transladar sua libido para um objeto sexual não incestuoso. Nesse sentido, o complexo de Édipo pode ser considerado como o nódulo das neuroses". Os restos do complexo de Édipo que, reprimidos pela censura, desaparecem da memória, mergulhando na pré-história individual revelam, todavia, sua existência durante a noite sob a forma, várias vezes observada, de sonhos de natureza incestuosa ou que revelam uma incompreendida hostilidade contra pessoas muito próximas e queridas. O equivalente feminino do complexo de Édipo denomina-se complexo de Electra (idem, ibidem, p. 12).
} 
quando o beberrão dizia alguma chalaça, e afinal, coitadas! iam-se habituando ao servilismo e à mentira.

Os pais ignorantes, viciados pelos costumes bárbaros do Brasil, atrofiados pelo hábito de lidar com escravos, entendiam que aquele animal era o único professor capaz de "endireitar os filhos".

Elogiavam-lhe a rispidez, recomendavam-lhe sempre que "não passasse a mão pela cabeça dos rapazes" e que, quando fosse preciso, "dobrasse por conta deles a dose de bolos".

Ângela, porém, não era dessa opinião: não podia admitir que seu querido filho, aquela criaturinha fraca, delicada, um mimo de inocência e de graça, um anjinho, que ela afagara com tanta ternura e com tanto amor, que ela podia dizer criada com os seus beijos - fosse lá apanhar palmatoadas de um brutalhão daquela ordem! "Ora! isso não tinha jeito!"

Mas o Vasconcelos sacava-lhe logo em cima: Que deixasse lá o pequeno com o mestre! [...] Mais tarde ele havia de agradecer aquelas palmatoadas!

Assim não sucedeu. Amâncio alimentou sempre contra o Pires o mesmo ódio e a mesma repugnância[...]. ${ }^{447}$

Estão, portanto, justificados o papel hostil que o pai representa no conteúdo onírico e a sua investidura na função do professor, pois este nada mais fora, no ponto de vista afetivo, que um desdobramento da autoridade paterna.

Olhemos agora para a natureza do crime que é punido no sonho e procuremos estabelecer as relações inconscientes entre a falta cometida e a cólera do velho Vasconcellos. Ao lado da revolta contra o pai, tivera uma ação saliente na infância do protagonista a outra componente do complexo de Édipo: a atração amorosa pela mãe. O autor não esconde mesmo o caráter libidinoso dos sentimentos do pequeno Amâncio para com sua mãe, como se pode constatar no seguinte trecho, que revela uma atividade sexual infantil muito intensa:

A própria idéia de sua mãe nunca lhe vinha só; havia sempre ao lado da veneranda imagem alguma recordação enfadonha e constrangedora. - As poucas vezes em que estavam juntos, o pai chegava no melhor da intimidade e Ângela se retraia, cortando em meio as carícias do filho, como se as recebera de um amante, em plena ilegalidade do adultério.

E a memória desses beijos a furto e medrosos, a memória desses carinhos cheios de sobressalto, relembravam-lhe as vezes que ele em pequeno se metia no quarto dos engomados, de camaradagem com as mulatas da casa que aí trabalhavam conjuntamente.

Era quase sempre pelo intervalo das aulas, ao meio do dia, quando o calor quebrava o corpo e punha nos sentidos uma pasmaceira voluptuosa.

[...]

Em casa do velho Vasconcellos havia, segundo o costume da província, grande número de criados; só no "quarto da goma" como lá se diz, reuniam-se quatro ou cinco. Umas costuravam; outras faziam renda, assentadas no chão, defronte da almofada de bilros; outras, vergadas sobre a 'taboa de engomar', passavam roupa a ferro.

Amâncio, quando criança, gostava de meter-se com elas, participar de suas conversas picadas de brejeirice, e deixar correr o tempo, deitado sobre saias, amolentando-se ao calor penetrante das raparigas, a ouvir, num êxtase mofino, o que elas entre si cochichavam com risadinhas estaladas à socapa. Por outro lado, as mulatas folgavam em tê-lo perto de si, achavam-no vivo e atilado, faziam-lhe perguntas maliciosas, só para "ver o que o demônio do menino respondia". E, logo que Amâncio dava a replica, piscando os olhos e mostrando a ponta da língua, caiam todas num ataque de riso, a olharem umas para as outras com intenção.

De resto, ninguém melhor do que ele para subtrair da despensa um punhado de açúcar ou de farinha, sem que Ângela desse por isso.

\footnotetext{
${ }^{447}$ Idem, ibidem.
} 
- O demoninho era levado!

E assim se foi tornando mulherengo, fraldeiro, amigo de saias.

A mãe, quando ouvia da varanda as risadas da criadagem, gritava logo pelo filho.

- Já vou, mamãe! Respondia Amâncio.

- Lá está o diabrete do menino às voltas com as raparigas no quarto da goma! Oh! que birra tinha ela disso!...

Mas Amâncio não se corrigia. É que ali ao menos não chegaria o pai. ${ }^{448}$

Esse trecho salienta a importância da coerção paterna sobre a atividade sexual infantil de Amâncio e nos mostra que o papel do velho Vasconcelos no sonho é o mesmo que ele desempenhava na infância do nosso herói: Amâncio veio a sentir-se merecedor da temida cólera dos outros tempos quando sua conduta amorosa atual fê-lo culpado de um amor pecaminoso como aquele que, em criança, tivera por sua própria mãe.

A decapitação pela guilhotina poderá talvez ser encarada, no ponto de vista psicanalítico, como um símbolo da castração.

Além desses fatores, devia pesar sobre o sentimento de auto-acusação de Amâncio outra circunstância mais recente, que não se deve deixar despercebida: a morte de seu pai. Uma vez no Rio de Janeiro, onde completava os estudos, Amâncio surpreendera em seu espírito sentimentos elevados com respeito ao pai, que deixara muito longe, numa cidade provinciana. Vieram as saudades e "doía-lhe a consciência por não ter sido melhor filho, como se o pobre rapaz de qualquer forma contribuíra para semelhante falta" ${ }^{449} \mathrm{E}$ os planos que então fazia de, voltando à província, tratar o velho "de modo tão carinhoso e tão amigo, que sua consciência ficasse, por uma vez, tranqüila a esse respeito" ${ }^{450}$ foram desfeitos repentinamente com a notícia da sua morte brusca, que veio surpreendê-lo pouco tempo antes dos exames.

Ora, na fase edipiana de seu desenvolvimento psíquico-sexual, e premido por seu ódio egoísta ao progenitor do mesmo sexo, a criança chega mesmo a desejar com veemência a sua morte. É tão pronunciada a "onipotência das idéias" na criança que quando essa morte se dá realmente, mesmo que seja muitos anos mais tarde, pode gerar-se no inconsciente do indivíduo um vago sentimento de culpabilidade, pois ele é levado a atribuir a si mesmo, pela simples circunstância de tê-lo alguma vez desejado, a responsabilidade de um acontecimento que se deu na realidade, por causas inteiramente alheias a essa aspiração infantil.

Antes de encerrar estas considerações, quero focalizar outro aspecto do sonho que estamos estudando e que concorda inteiramente com as afirmações de Freud sobre os sonhos de exame. Diz o criador da psicanálise: os sonhos dessa natureza evocam sempre exames em que a pessoa saiu triunfante e jamais aqueles em que foi reprovada. Esses sonhos de angústia, que costumam apresentar-se quando no dia seguinte temos de resolver alguma cousa importante, buscariam, pois, no passado, uma ocasião em que a angústia se revelara injustificada e fora desmentida pelo êxito. Essa circunstância valeria, portanto, por um estímulo otimista, fazendo ver ao indivíduo que não deve temer a dificuldade que se apresenta, pois numa situação em que tivera igualmente medo, nada de mau lhe aconteceu.

No sonho de Amâncio, verifica-se realmente esse fato, podendo notar-se, pela coincidência de certos detalhes, que o exame a que ele devia submeter-se no início do desenvolvimento onírico é o mesmo em que, na sua infância, ele se saíra muito bem. $\mathrm{Na}$ descrição do sonho, escreve o autor:

Os examinadores surgiam-lhe terríveis, ríspidos, armados de palmatória, e todos com aquela feia catadura do seu ex-professor de português no Maranhão. Pelo incoerente prisma do sonho, o concurso acadêmico amesquinhava-se às ridículas proporções do

\footnotetext{
${ }_{448}^{4}$ A. Azevedo, Casa de pensão, op. cit., p. 64

${ }^{449}$ Idem, ibidem, p. 182.

${ }^{450}$ Idem, ibidem, p. 268.
} 
exame de primeiras letras. Era a mesma salinha do mestre-escola, a mesma banca de paparaúba manchada de tinta, o mesmo fanhoso Sotero dos Reis presidindo a mesa.

Leiamos agora nas primeiras páginas do romance:

Só aos doze anos fez o seu exame de português na aula do Pires. Houve muita formalidade. A congregação era presidida pelo Sotero dos Reis; havia vinte e tantos examinandos. Amâncio tremia naqueles apuros. Não tinha em si a menor confiança. Foi, contudo "aprovado plenamente". Mas não sabia nada, quase que não sabia ler. ${ }^{451}$

Para não me tornar demasiado extenso, deixo de abordar outras questões mais complexas e que exigem um estudo mais demorado, como, por exemplo, a de saber até que ponto o sonho de que acabo de me ocupar representa uma projeção do inconsciente do autor e pode contribuir para o seu retrato psicanalítico. A obra de Aluísio Azevedo é, aliás, rica em aspectos interessantes para a psicanálise e oxalá que alguém se lembre de aproveitar melhor e mais largamente o excelente material que ela pode oferecer.

${ }^{451}$ Idem, ibidem. 